\title{
Preliminary Results of the 3-D Inversion of Magnetotelluric Data in the Southern Sub province of Borborema Province, Northeast Brazil
}

\author{
Andrea Santos-Matos ${ }^{12}$, Antonio Lopes Padilha ${ }^{1}$, Reinhardt Adolfo Fuck ${ }^{3}$, Marcelo Banik Pádua ${ }^{1}$ \\ ${ }^{1}$ Instituto Nacional de Pesquisas Espaciais - INPE/DIDGE/GEOMA - Grupo de Geomagnetismo \\ ${ }^{2}$ Universidade Federal do Pampa \\ ${ }^{3}$ Universidade de Brasília
}

Copyright 2019, SBGf - Sociedade Brasileira de Geofísica

This paper was prepared for presentation during the $16^{\text {th }}$ International Congress of the Brazilian Geophysical Society held in Rio de Janeiro, Brazil, 19-22 August 2019.

Contents of this paper were reviewed by the Technical Committee of the $16^{\text {th }}$ International Congress of the Brazilian Geophysical Society and do not necessarily represent any position of the SBGf, its officers or members. Electronic reproduction or storage of any part of this paper for commercial purposes without the written consent of the Brazilian Geophysical Society is prohibited.

\begin{abstract}
The present work shows a preliminary interpretation of the deep tectonic structures of the continental lithosphere in the southern sub province of the Borborema Province, in northeast Brazil. Information on the subsurface distribution of electrical conductivity was derived from 102 magnetotelluric (MT) stations disposed along 5 profiles that cut the main tectonic units of this sub province. These data were processed and modeled by advanced 3D techniques currently available for studies of electromagnetic induction within the Earth. Preliminary interpretation suggests that several of the observed anomalies are correlated mainly to effects of Neoproterozoic oceanic crust subduction and subsequent collision in at least two regions of the study area. One of them is located under the central region of the Tucano Basin, probably related to the subduction of an oceanic basin to the east, and the other under the Central domain of the Borborema Province, preliminarily interpreted as a subduction zone to the north.
\end{abstract}

\section{Introdução}

A região de estudo está localizada principalmente no domínio tectônico Sul da Província Borborema. A estrutura mais proeminente na superfície dessa região é o sistema de rifte intracontinental Recôncavo-TucanoJatobá (RTJ), aproximadamente delimitado pelas latitudes $8^{\circ}$ e $13^{\circ} \mathrm{S}$ e longitudes $36^{\circ}$ e $40^{\circ} \mathrm{W}$. A origem desse sistema está associada aos estágios iniciais dos processos geodinâmicos que levaram à formação do Atlântico Sul e da margem continental brasileira, culminado com a separação definitiva entre América do Sul e África. Os esforços distensivos responsáveis pelo rifteamento teriam atuado entre Mesojurássico (175 Ma) e Eocretáceo (145 Ma) (Milani \& Davison, 1988). Ao contrário das bacias de margem continental, que evoluíram ao estágio de margem passiva, as bacias Recôncavo, Tucano e Jatobá se constituíram em ramo abortado do rifte da margem Leste do Brasil (Chang et al., 1992). As estruturas do embasamento exerceram forte influência na geometria final do arcabouço estrutural das bacias (Milani \& Davison, 1988; Magnavita, 1992; Magnavita et al., 1994; Costa et al., 2007), que compreende uma série de hemi-grabens assimétricos, separados por altos do embasamento e falhas de transferência oblíquas, com cada hemi-graben tendo suas próprias características estruturais e estratigráficas.

Este trabalho tem como objetivo o estudo geotectônico de estruturas profundas da litosfera continental, incluindo crosta e manto superior, de modo a contribuir para o entendimento da tectônica regional da sub província Sul da Província Borborema, com ênfase no sistema de rifte RTJ. Para tanto, foi mapeada a distribuição de condutividade elétrica em diferentes profundidades litosféricas, por meio de perfis de sondagens MT posicionados ortogonalmente às direções estruturais predominantes (Figura 1).

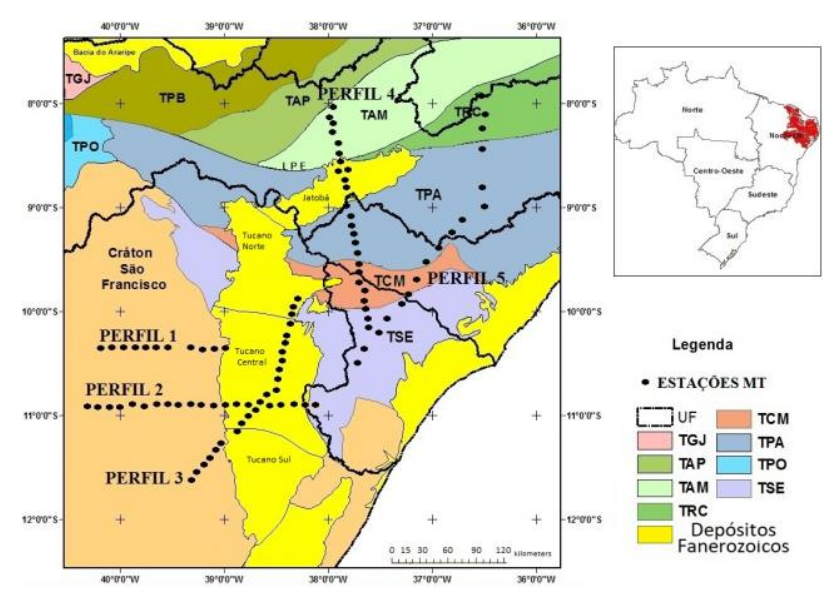

Figura 1. Compartimentação da Província Borborema em domínios e terrenos tectono-estratigráficos, segundo Santos (1999, 2000). A localização das estações MT é mostrada por pontos pretos, identificando-se também os 5 perfis discutidos no texto. Os diferentes terrenos e estruturas são: TGJ - Terreno Granjeiro, TMO - Terreno Monte Orebe, TPO - Faixa Riacho do Pontal, TPB Terreno Piancó-Alto Brígida, TAP - Terreno Alto Pajeú, TAM - Terreno Alto Moxotó, TRC - Terreno Rio Capibaribe, TPA - Maciço Pernambuco-Alagoas, TCM domínios Canindé e Marancó, TSE - Faixa Sergipana, LPE - Lineamento Pernambuco.

\section{Metodologia}

O método MT envolve a aquisição de dados naturais do campo eletromagnético de amplitude bastante baixa e em amplo espectro de frequências (maiores detalhes sobre o método podem ser obtidos em Simpson \& Bahr, 2005 e Chave \& Jones, 2012). O sucesso de um levantamento MT depende da disponibilidade de equipamentos confiáveis, escolha adequada dos sítios para sua 
instalação e um processamento robusto que consiga eliminar ruídos dos sinais adquiridos. A interpretação dos dados MT depende diretamente da qualidade da estimativa das funções de transferência entre os componentes do campo eletromagnético medido (elementos do tensor de impedância). Assim, é necessário que sejam obtidas com a maior precisão possível.

Os dados utilizados neste trabalho foram processados, usando programas computacionais de domínio público para uso acadêmico (descritos em Santos, 2012). Inicialmente, realizou-se o processamento de cada estação MT com o objetivo de preparar os dados para a inversão 3D. A primeira etapa do processamento consistiu em sua organização até a primeira visualização por meio de pseudosseções. Os dados foram processados seguindo o fluxograma de processamento adotado pelo grupo de pesquisa em Geomagnetismo da Divisão de Geofísica Espacial do Instituto Nacional de Pesquisas Espaciais - GEOMA/INPE (Figura 2)

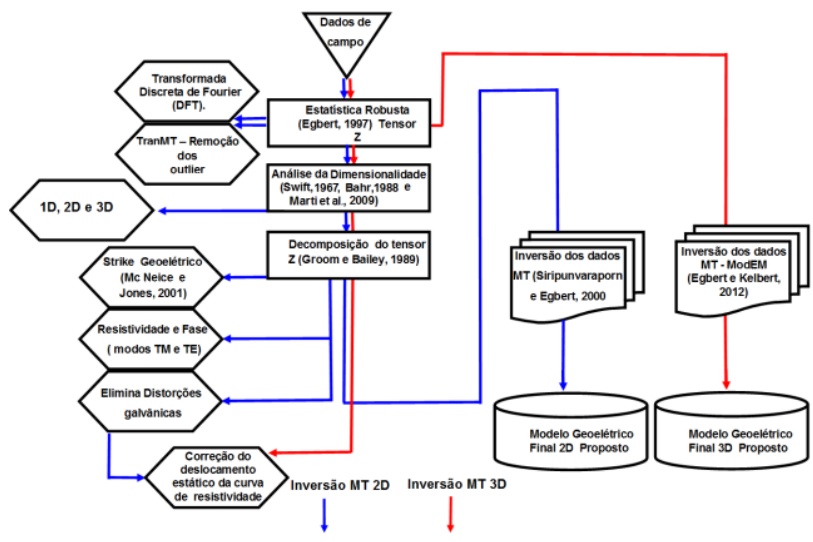

Figura 2. Fluxograma descrevendo as sucessivas etapas para processamento de dados magnetotelúricos.

Para verificar a dimensionalidade das estruturas regionais foi aplicado o código WALDIM (Martí et al. 2009), que se utiliza de uma série de invariantes de rotação para propor uma dimensionalidade regional, conforme apresentado por Weaver et al. (2000). De acordo com o código WALDIM, foi possível observar que boa parte dos dados, ao longo de toda a faixa de frequências analisada, obedece a uma condição 3D. Somente dados mais rasos, com períodos inferiores a $1 \mathrm{~s}$ e localizados na região das bacias Tucano e Jatobá, têm características 1D. A partir desses resultados optou-se por realizar inversão 3D dos dados MT, a qual consiste na obtenção de um modelo de distribuição de condutividades sob toda a região de medidas, que ajuste, dentro de certos limites pré-estabelecidos (error floors), os diferentes parâmetros obtidos nos levantamentos de campo (tensor de impedância e função de transferência magnética (tipper) em função da frequência).

\section{Inversão 3D}

O código ModEM de inversão 3D de dados MT (Egbert \& Kelbert, 2012) foi usado para obter um modelo suave de distribuição de condutividade em subsuperfície. Para a inversão 3D foram utilizados dados das 102 estações, distribuídas em matriz não regular. O espaçamento entre essas estações foi de $20 \mathrm{~km}$ para os perfis 1, 2, 3 e 5, e $10 \mathrm{~km}$ para o perfil 4 (Figura 1). O sistema de coordenadas foi rotacionado em $50^{\circ}$ para leste, paralelo à principal estrutura geoelétrica observada na superfície da região. A resistividade designada para a água do mar foi de $0,3 \Omega . m$, estando este valor fixado durante toda a etapa de inversão. Os dados foram calculados em 15 períodos, distribuídos logaritmicamente entre $0,1 \mathrm{~s}$ e 10000 s, com quatro períodos por década. O modelo de entrada utilizado para a inversão foi o de semi-espaço com resistividade de $100 \Omega$.m, tendo sido incluídas na inversão todas as componentes do tensor de impedância. $\mathrm{O}$ ajuste da inversão 3D foi considerado bom, tendo sido obtido para o modelo final o valor de $\mathrm{rms}=3.9$ (equivalente a erro inferior a $20 \%$ para os elementos do tensor de impedância). A Figura 5 mostra o modelo 3D obtido, com a localização das estações e a identificação dos perfis na superfície.

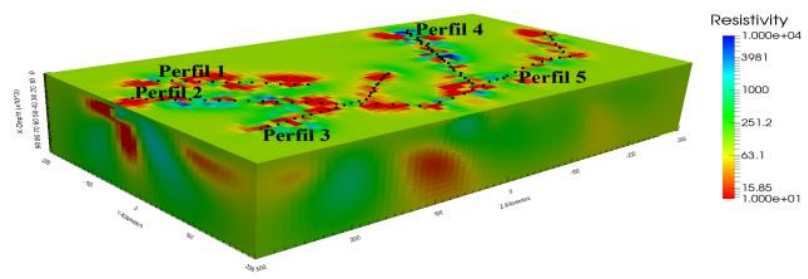

Figura 5. Distribuição geoelétrica em superfície da sub província Sul da Província Borborema a partir da inversão 3D de dados magnetotelúricos.

\section{Resultados Preliminares da Inversão 3D}

Os resultados são discutidos a partir de seções verticais do modelo 3D da Figura 5. Para facilitar essa discussão é utilizada como referência a compartimentação tectônica para a parte Sul da Província Borborema, separada em domínios e terrenos tectono-estratigráficos reconhecidos na superfície (Santos, 1999; 2000) (Figura 1).

Os perfis 1 e 2 são paralelos, iniciando-se a oeste sobre o bloco Gavião do Cráton do São Francisco e cortando o bloco Serrinha desse mesmo cráton. Enquanto o perfil 1 fica limitado ao Cráton, o perfil 2 estende-se mais para leste cortando integralmente a bacia Tucano Central e chegando à Faixa Sergipana. As figuras 6 e 7 mostram seções verticais ao longo desses dois perfis.

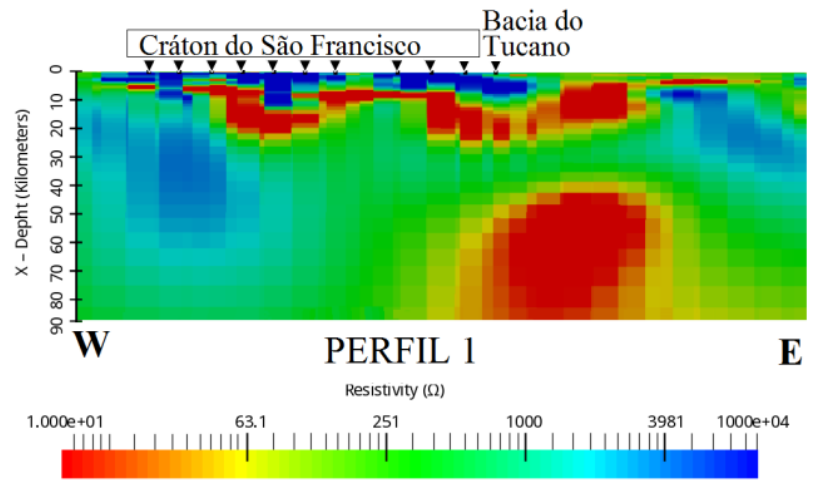

Figura 6. Seção vertical de resistividades sob o perfil 1 a partir do modelo inverso 3D. 
Santos-Matos, A., Padilha, A. L., Fuck, R.A., Pádua, M. B.

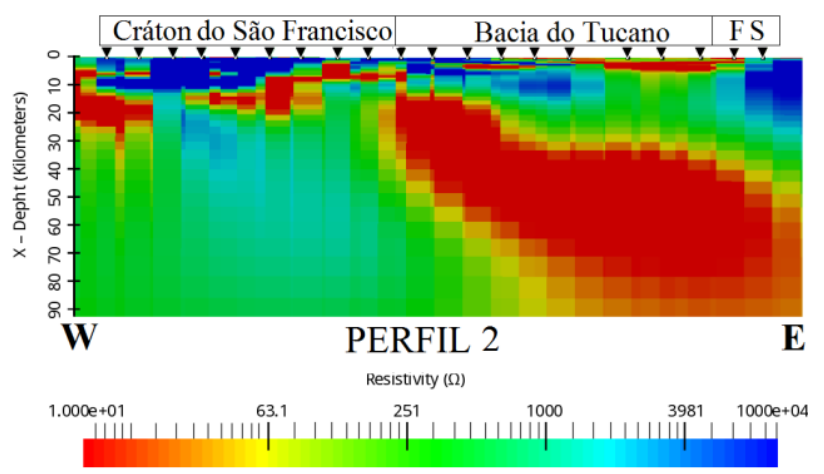

Figura 7. Seção vertical de resistividades sob o perfil 2 a partir do modelo inverso 3D. FS - Faixa Sergipana.

Conforme esperado, a resistividade elétrica é elevada (próxima a 10.000 ohm.m) na crosta superior do Cráton do São Francisco. Em profundidades da crosta médiasuperior (10 a $20 \mathrm{~km}$ ) aparecem os corpos condutores observados na seção horizontal. São caracterizados por estruturas aproximadamente horizontais e que podem ser relacionados a rochas intrusivas. Essa região do cráton experimentou episódios magmáticos desde sua consolidação no Paleoproterozóico, conforme documentado pelo magmatismo kimberlítico que se originou no Neoproterozóico dentro e no entorno do bloco Serrinha. Nesse caso, durante a cristalização desses magmas, o influxo de $\mathrm{CO} 2$ na crosta pode ter favorecido a deposição de quantidade significativa de grafita. Outra hipótese seria a relação desses condutores com eventos de fechamento de oceano e colisão de terrenos nessa borda do cráton. Nessa região está exposto o cinturão do Rio Itapicuru, composto por rochas vulcanossedimentares de idade Paleoproterozoica e que contém os maiores depósitos de ouro do nordeste do Brasil.

O perfil 2 mostra que sob a Bacia do Tucano aparecem corpos condutores na crosta superior (os condutores observados em maiores profundidades sob o perfil 1 não são significativos pela ausência de dados experimentais sob a bacia nesse perfil). Corpos condutores similares foram observados no perfil 2D analisado por Santos et al. (2014) sob a Bacia do Jatobá e interpretados como fluidos altamente salinos que migraram desde a bacia até uma zona fraturada na crosta superior (nas proximidades do Lineamento Pernambuco) que teria sido reativada em tempos atuais. Devido à limitação computacional para rodar a inversão 3D, nem todos os dados disponíveis são utilizados na inversão e por isso o modelo 3D tem menor resolução que o 2D. Dessa forma, não é possível verificar se essa mesma hipótese seria válida para a região da Bacia do Tucano. Além dessa hipótese de fluidos salinos, outra alternativa seria a deposição de carbono como filmes em superfície de zonas de fraturas. Esforços e movimentos tectônicos favoreceriam a grafitização, de forma que essas anomalias de condutividade abaixo da Bacia do Tucano poderiam ser associadas com a origem da bacia. Ambas as hipóteses podem ser usadas para apoiar o modelo sugerido por Ussami et al. (1986) para a origem do sistema de rifts RTJ, como resultando de importante movimentações eminentemente crustais durante a abertura do Oceano Atlântico Sul.
Também no perfil 2, observa-se a forte estrutura condutora detectada pela seção horizontal sob a Bacia Tucano Central. Ela aparece como uma estrutura inclinada, mergulhando na direção leste sob a bacia. Considerando a hipótese de que os condutores mapeados neste trabalho estejam relacionados com zonas de subducção, esses resultados podem condicionar sua polaridade de mergulho. Entre os modelos sugeridos para a fase original da evolução regional, Figueiredo (1989) propõe que extenso oceano teria estado presente a leste do cinturão ItabunaSalvador-Curaçá e que a subducção de crosta oceânica para oeste seria responsável pelo desenvolvimento do cinturão Rio Itapicuru como uma bacia do tipo back-arc e do cinturão Salvador-Curaçá como um arco magmático. Outros autores (por exemplo, Ruggiero e Oliveira, 2010) sugerem ao contrário o desenvolvimento de uma bacia oceânica a oeste do cinturão Itabuna-Salvador-Curaçá, com subducção da crosta oceânica para o leste e formação simultânea de uma bacia de back-arc em que foram geradas as rochas do Rio Itapicuru. Nossos resultados podem ser usados nesse caso como suporte para a segunda hipótese. Um aspecto a ser ainda investigado refere-se à limitação espacial dessa zona de mergulho, condicionada a parte da Bacia Tucano Central.

A Figura 8 mostra seção vertical ao longo do perfil 3 . Esse perfil também se posiciona exclusivamente sobre 0 Cráton do São Francisco e a Bacia do Tucano (principalmente cruzando quase longitudinalmente sua parte central). No cráton, ele corta a parte sul do bloco Serrinha que nesta região não apresenta qualquer anomalia de condutividade em profundidades crustais. Ao contrário, o bloco é caracterizado por estruturas de alta resistividade que se estendem até 0 manto superior (cerca de $70 \mathrm{~km}$ de profundidade). O condutor no extremo sudoeste do perfil tem baixa resolução pela ausência de estações MT nessa região. Da mesma forma que no perfil 2 , a anomalia de alta condutividade na crosta superior se estende horizontalmente por toda a bacia, uma indicação de sua importância regional. O perfil também indica a limitação lateral da anomalia de alta condutividade observada no manto, concentrada na Bacia Tucano Central. Apresenta também, o mesmo condutor inclinado profundo detectado no perfil 2 sob a Bacia do Tucano e interpretado como subducção de crosta oceânica para leste.

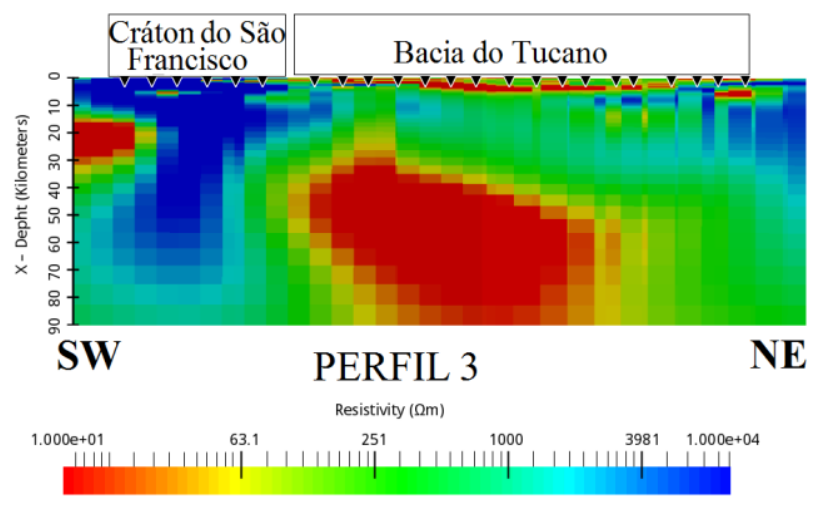

Figura 8. Seção vertical de resistividades sob o perfil 3 a partir do modelo inverso 3D. 
A figura 9 possibilita comparação do resultado obtido pela inversão 3D sob o perfil $4 \mathrm{com}$ aquele derivado da inversão 2D sob esse mesmo perfil (Santos et al., 2014). Esse perfil inicia-se ao sul sobre a Faixa Sergipana, corta os domínios Canindé e Marancó, o Maciço PernambucoAlagoas e a Bacia do Jatobá, situados na sub província Sul da Província Borborema, e estende-se sobre o Terreno Alto Moxotó, na Zona Transversal, ou sub província Central, da província.

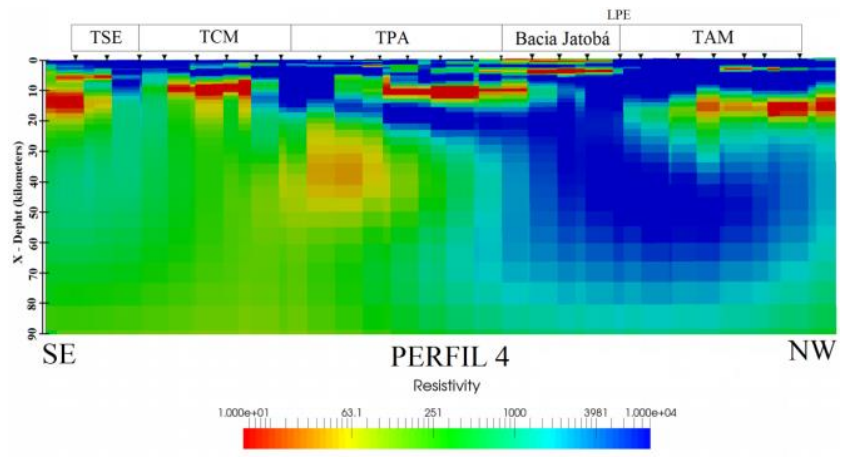

Figura 9. Seção vertical do modelo geoelétrico 3D sob o perfil 4. TAM - Terreno Alto Moxotó; TSE - Faixa Sergipana; TCM - domínios Canindé e Marancó; TPA Maciço Pernambuco-Alagoas; LPE - Lineamento Pernambuco.

O modelo sob o perfil 4 mostra valores de resistividade bastante altos próximo da superfície, com exceção da região onde afloram os sedimentos da Bacia Jatobá. Essa alta resistividade é associada a baixo fraturamento nas rochas desses diferentes domínios, não permitindo a interconexão de fluidos que facilitem a condução eletrolítica. Também, a crosta média-inferior nos diferentes terrenos é bastante distinta e inomogênea, refletindo a presença de blocos de natureza diversa, com evolução tectônica distinta. Em maiores profundidades da crosta inferior e no manto superior há nítida distinção entre os terrenos das sub províncias Sul e Central da província, com a definição de duas regiões geoeletricamente distintas: na sub província Sul é registrada resistividade moderada, em torno de 250 ohm.m, enquanto a partir da Bacia do Jatobá e na sub província Central as resistividades atingem valores da ordem de 10.000 ohm.m. Esse resultado, já observado por Santos et al. (2014), em conjunto com dados sísmicos e gravimétricos disponíveis, levou esses autores a concluir que a crosta na região da sub província Sul teria sido significativamente estirada no Cretáceo, durante a abertura do Oceano Atlântico Sul. O Terreno Alto Moxotó, na Zona Transversal, teria funcionado como região de maior resistência a esse estiramento, fazendo com que o afinamento crustal fosse mais expressivo nos subdomínios da porção SE do perfil. O incremento de condutividade estaria relacionado à refertilização do manto superior empobrecido em elementos incompatíveis por material enriquecido proveniente do manto mais profundo durante esse processo de estiramento. Os resultados da inversão 3D confirmam essa diferenciação no manto, mas também indicam a presença de importantes corpos condutores na crosta sob o Terreno Alto Moxotó, que podem estar relacionados a processos de amalgamação da província durante o Neoproterozóico.

Também, a região onde a Bacia do Jatobá está localizada apresenta forte condutor no modelo 2D, que se estende desde a crosta superior até profundidades do manto. Análises de propagação do sinal indicaram que no modelo $2 \mathrm{D}$ não há resolução para esse condutor em profundidades superiores a $15 \mathrm{~km}$, a qual foi considerada como profundidade máxima para sua ocorrência. O aumento da condutividade abaixo da Bacia do Jatobá foi interpretado por Santos et al. (2014) como associada a condução iônica em zona de fratura reativada e preenchida com fluido de alta salinidade. O modelo 3D fornece resolução mais adequada para a profundidade máxima do condutor que efetivamente se limita à crosta superior, dando suporte à interpretação apresentada naquele trabalho.

Por fim, a Figura 10 mostra a distribuição de resistividades mapeada sob o perfil 5 . Esse perfil é o que mais se aproxima da margem continental e como tal é o mais afetado por efeitos 3D gerados no contato do continente com a água salina do mar (efeitos de costa). Ele atravessa a Faixa Sergipana, incluindo os domínios Canindé e Marancó, e Maciço Pernambuco-Alagoas na sub província Sul e o terreno Rio Capibaribe na Zona Transversal da província. A mesma estruturação heterogênea composta por blocos condutivos e resistivos é observada na crosta médio-superior sob os diversos terrenos da sub província Sul, com a crosta inferior e manto apresentando também valores de condutividade similares aos do perfil 4. A grande diferença, porém, ocorre nas proximidades do contato com a Zona Transversal, terreno Rio Capibaribe, que apresenta importante condutor mergulhando desde a crosta inferior até profundidades do manto. A existência e geometria desse condutor podem significar o mapeamento de estruturas relacionadas com a formação da província, no Neoproterozóico, indicando subducção de crosta oceânica para o norte. Esse resultado pode ser importante para dar suporte a um dos processos propostos para formação da Província Borborema (aglutinação de blocos alóctones; Fuck et al. 2008).

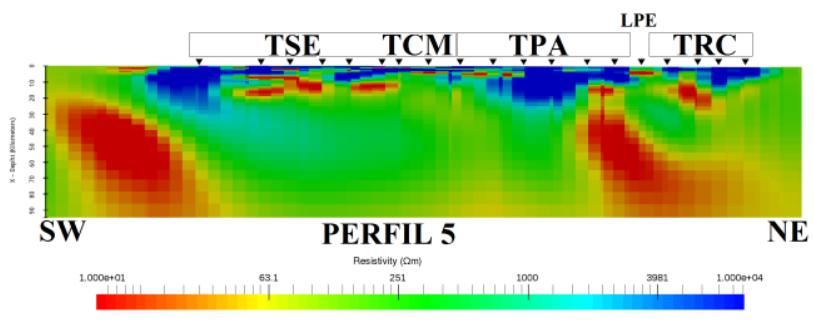

Figura 10. Seção vertical de resistividades sob o perfil 5. TRC - Terreno Rio Capibaribe; TSE - Faixa Sergipana; TCM - domínios Canindé e Marancó; TPA - Maciço Pernambuco-Alagoas; LPE - Lineamento Pernambuco.

\section{Conclusões}

Com o uso de inversão 3D de dados magnetotelúricos na região da sub província Sul da Província Borborema, foram identificadas várias anomalias condutoras associadas a processos tectônicos ocorridos no passado 
Santos-Matos, A., Padilha, A. L., Fuck, R.A., Pádua, M. B.

nessa região do NE do Brasil. A análise preliminar do modelo de inversão 3D obtido sugere que várias das anomalias observadas se relacionam principalmente a efeitos de processos de subducção de crosta oceânica e subsequente colisão de terrenos em pelo menos duas regiões da área em estudo. Os perfis 2 e 3 indicam um condutor crustal inclinado, interpretado como subducção de bacia oceânica formada a oeste do cinturão ItabunaSalvador-Curaçá, mergulhando para leste sob a Bacia Tucano Central. O perfil 5 mostra condutor similar inclinado para norte, interpretado como subducção de crosta oceânica para norte, sob a sub província Central, ou Zona Transversal da Província Borborema.

Identificaram-se também estruturas condutoras na crosta superior, sob os pacotes sedimentares das bacias amostradas (Tucano e Jatobá). Esta parece ser uma característica regional desse sistema de riftes e que pode estar relacionada aos mecanismos de sua geração (possível existência de zonas fraturadas na crosta superior de ambas as bacias amostradas).

\section{Agradecimentos}

Este estudo foi financiado pelo CNPq (573713/2008-1 e 407252/2016-9). Agradecemos ao ON por disponibilizar os equipamentos geofísicos (PEG-BR) e ao Programa EMBRACE do INPE pelas facilidades computacionais.

\section{Referências}

Chang K, Kowsmann RO, Figueiredo AMF \& Bender AA, 1992. Tectonics and stratigraphy of the East Brazil Rift system: an overview. Tectonophysics, 213: 97-138.

Costa IP, Bueno GV, Milhomem OS, Silva HSRL \& Kosin MD, 2007. Sub-bacia de Tucano Norte e Bacia de Jatobá. Boletim de Geociências da Petrobras, 15: 445-453.

Egbert G.D. \& Kelbert A, 2012. Computational recipes for electromagnetic inverse problems. Geophysical Journal International, 189: 251-267.

Figueiredo, M.C.H. 1989. Geochemical evolution of eastern Bahia, Brazil: a probable Early Proterozoic subduction-related magmatic arc, Journal of South American Earth Sciences, 2, 131- 145.

Fuck RA, Brito-Neves BB, Schobbenhaus C. 2008. Rodinia descendants in South America. Precambrian Research, 160, 108-126.

Magnavita LP, 1992. Geometry and kinematics of the Recôncavo-Tucano-Jatobá rift, NE Brasil. Tese de Doutorado, Universidade de Oxford, 493p

Magnavita LP, Davison I \& Kusznir NJ, 1994. Rifting, and uplift history of the Recôncavo-Tucano-Jatobá Rift, northeast Brazil. Tectonics, 13: 367-388.

Martí A, Queralt P, Ledo J. 2009. WALDIM: A code for the dimensionality analysis of magnetotelluric data using the rotational invariants of the magnetotelluric tensor. Computers and Geosciences, 35, 2295-2303.

Milani EJ \& Davison I, 1988. Basement control and transfer tectonics in the Recôncavo-Tucano-Jatobá rift, Northeast Brazil. Tectonophysics, 154: 41-70.
Ruggiero A \& Oliveira EP. 2010. Caracterização de vulcânicas adakíticas e cálcio-alcalinas no greenstone belt do rio Itapicuru, Bahia: petrogênese e implicações geodinâmicas, Revista Brasileira de Geociências, 40, 1 18.

Santos ACL, 2012. Imageamento magnetotelúrico de estruturas da litosfera na porção $\mathrm{SE}$ da província Borborema. Tese de Doutorado, Universidade de Brasília, 159p.

Santos ACL, Padilha AL, Fuck RA, Pires ACB, Vitorello I \& Pádua $M B, 2014$. Deep structure of a stretched lithosphere: Magnetotelluric imaging of the southeastern Borborema province, NE Brazil. Tectonophysics 610:3950. doi:10.1016/j.tecto.2013.10.008.

Santos EJ. 1999. Programa levantamentos geológicos básicos do Brasil: carta geológica. Belém do São Francisco, Folha SC.24-X-A. Escala 1:250.000. Brasília: CPRM (CD-ROM).

Santos EJ. 2000. Contexto tectônico regional. In: Medeiros, V.C. (Ed.) Programa levantamentos geológicos básicos do Brasil. Aracaju NE, Folha SC.24-X. Escala 1:500.000. Brasília: CPRM. 2, CD-ROM.

Simpson F \& Bahr K, 2005. Practical Magnetotellurics. Cambridge University Press, 270p.

Ussami N, Karner GD \& Bott MHP, 1986. Crustal detachment during South Atlantic rifting and formation of Tucano-Gabon basin system. Nature, 322: 629-632.

Weaver JT, Agarwal, A.K \& Lilley FEM. 2000. Characterisation of the magnetotelluric tensor in terms of its invariants. Geophysical Journal International, 141, 321-336. 